\title{
Improving Signal Strength in Wireless Mobile Communication using Diversity Combining Technique over Rayleigh Fading Channels
}

\author{
Aarti Pandey \\ Electronics and Communication \\ D.I.T, Dehradun \\ India
}

\author{
Vishal Gupta, Ph.D \\ Electronics and Communication \\ G.R.D-IMT, Dehradun \\ India
}

\author{
S.C Gupta, Ph.D \\ Electronics and Communication \\ G.R.D-IMT, Dehradun \\ India
}

\begin{abstract}
The error probability floor evolves due to performance loss, thus there is a requirement of high energy and high bandwidth to get a desired link. The branches are assumed to be Rayleigh fading. With the increase number of receiver the signal to noise ratio to be improved and bit error rate of all branches are compared. This work confirms the benefit of choosing 2x2MIMO system instead of 1 transmits 2 receive MRC case.
\end{abstract}

\section{Keywords}

Fading channels, Receive Diversity - Selection Diversity, Equal Gain Combining, Maximal Ratio Combining (MRC), Transmit diversity -Alamouti's Scheme, Multiple InputMultiple Output (MIMO), Rayleigh fading, Bit error rate, Performance loss.

\section{INTRODUCTION}

Wireless communication has become an important part of daily routine of human being, for voice as well as data traffic. Wireless network provides high speed mobility, Time varying fading results unreliable wireless transmission.

\section{FADING}

In case of destructive interference the power of signal significantly reduced at receiver that is known as fading.

The quality of signal get degrade at the receiver due to deep fades that may occur at particular frequency or time or in space ,this make the detection and decoding of signal impossible at receiver.

If the signal arriving at receiver are not in coherence than multipath fading arises, to mitigate multipath fading in wireless channel transmitter power control method is used, in this method transmitter on other side of the link preprocessed the signal according to the channel condition experienced by receiver on one side of the link, in order to overcome the effects of channel.

But in case of different uplink and downlink frequencies some problems occurs in this method due to dynamic range of transmitter, transmitter does not have the knowledge of channel information experienced by the receiver, so in this case this information is feedback to transmitter from the receiver.
Diversity techniques are other effective techniques to overcome these problems. [1]

\subsection{Parameter of Fading}

Multipath spread- it defines maximum path delay between information signals in the channel.

- $\quad$ Coherence bandwidth- it defines the range of frequencies in which transfer function of channel remain constant.

- $\quad$ Coherence time- it defines the time period during which the propagating wave (laser or maser beam) can be considered coherent.

\subsection{CLASSIFICATION OF FADING}

\subsubsection{Large Scale Fading}

This type of fading is the result of reduction in signal strength over large distances in the propagation path of signal.

\subsubsection{Small Scale Fading}

This type of fading is the rapid changes of amplitudes, phases or multipath delays of radio signal over small distances and small period of time. [5]

Small Scale Fading

(Based on multipath time delay spread)

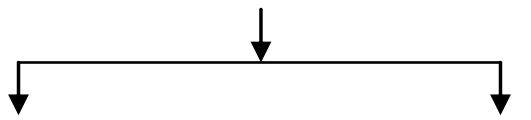

Flat Fading

Frequency

Selective

Fading

BW of Signal $<$ BW of Channel Channel

Delay Spread $<$ Symbol Period Delay Spread $>$ Symbol Period
BW of Signal $>\mathrm{BW}$ of 
Small Scale Fading

(Based on Doppler spread)

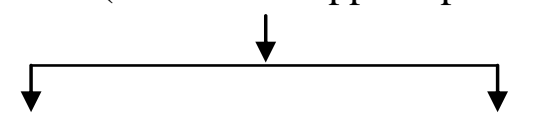

Flat Fading

Slow Fading

1. High Doppler spread

1. Low Doppler spread

2. Coherence Time $<$ Symbol period

2. Coherence Time > Symbol period

3. Channel variation faster than

3. Channel variation

Signal variation

band

Slower than Base -

Signal variations

\subsection{Classification of Fading Channels}

Classification of fading channels depending on the characteristics of signal to be transmitted and the parameters of channels.

\subsubsection{Frequency Non Selective Versus} Frequency Selective

Frequency non selective fading is when all the frequency components of a signal undergo generally same level of fading. It occurs when the transmitted signal bandwidth is small as compared to coherence bandwidth of channel i.e. $\mathrm{B} \ll<\mathrm{B}_{\mathrm{c}}$ it is also known as flat fading. Frequency selective fading is when frequency components of transmitted signal attenuated differently. It occurs when transmitted signal bandwidth is large as compared to coherence bandwidth i.e. $\mathrm{B}>>\mathrm{B}_{\mathrm{c}}$

\section{DIVERSITY TECHNIQUES}

To improve the performance of wireless communication system over a fading channel diversity technique is used in the receiver end.

In this technique multiple copies of same information signal are provided to receiver over two or more different communication channel. Thus the main concept of using diversity techniques is repetition or redundancy of information signal to provide reliable wireless radio communication by selecting the signal of higher strength. The decisions made in diversity technique are unknown to receiver.

\subsection{Types of Diversity Techniques}

\subsubsection{Microscopic technique}

This technique is used to counteract small scale fading that is to avoid deep signal fading under distance of just a few wavelengths.

\subsubsection{Macroscopic diversity}

This technique is used to counteract large scale fading which occurs due to shadowing problems. [5]

\subsection{Diversity Combining Techniques 3.2.1 . Selection Combining}

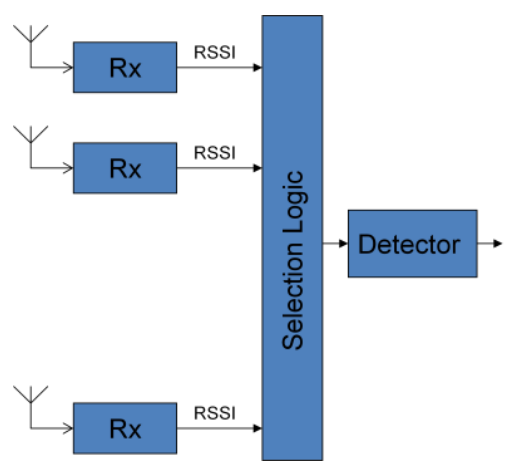

Uses $\mathrm{M}$ receivers-branches, compares signals and selects the best one.

\subsubsection{Equal Gain Combining}

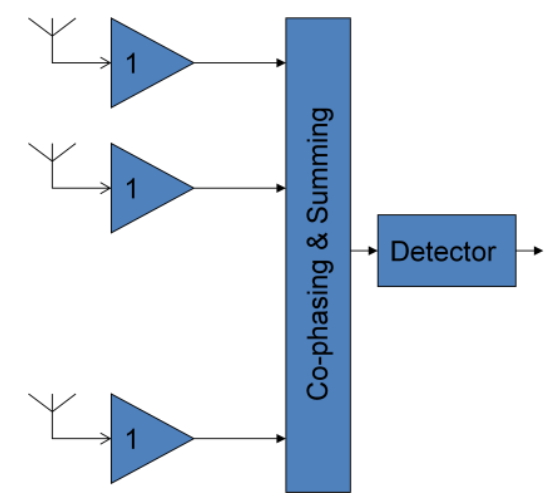

All branches are merely co-phased and summed

\subsubsection{Maximal Ratio Combining (MRC)}

Each branch is weighted before summation in proportion to its own signal-to-noise ratio. Slightly better performance than EGC but more complex. [8]

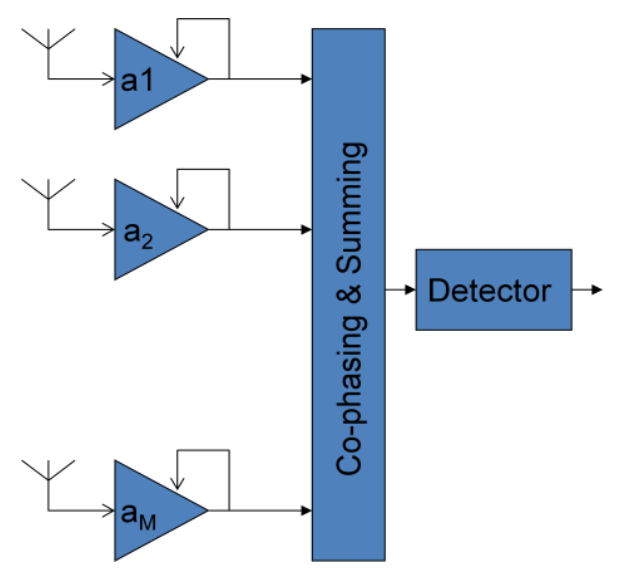




\section{THE NEW DIVERSITY SCHEME}

\subsection{Two Branch Diversity Techniques with One Receiver}

Fig. 1

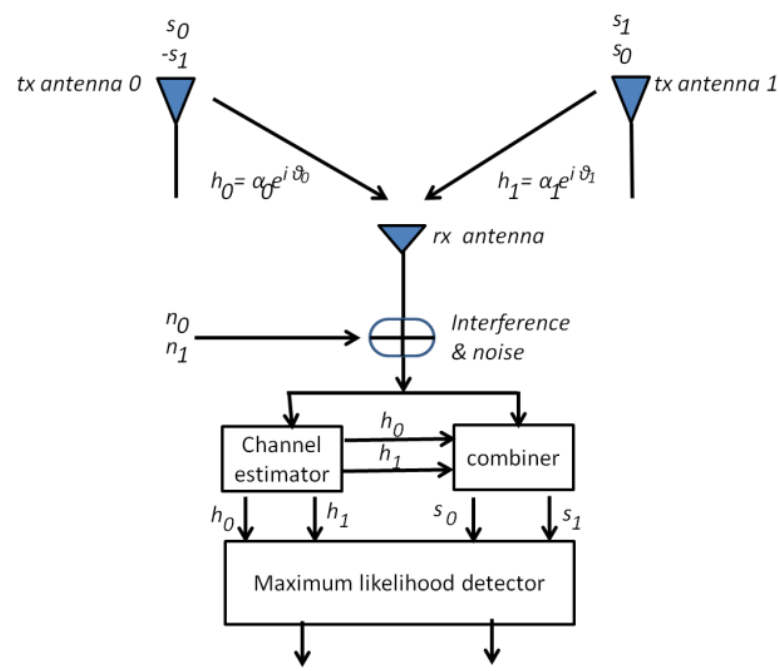

In this scheme two transmit antennas and one receive antenna be used and defined by following function:

The encoding and transmission sequence of information symbols at

- the transmitter;

- The combining scheme at the receiver

- The decision rule for maximum likelihood detection

Table A. The Encoding and Transmission sequence for the Two-Branch transmit Diversity Scheme

\begin{tabular}{|c|c|c|}
\hline Time & antenna $\mathbf{0}$ & antenna $\mathbf{1}$ \\
\hline $\mathrm{T}$ & $s_{0}$ & $s_{1}$ \\
\hline $\mathrm{t}+\mathrm{T}$ & $-s_{1}^{*}$ & $s_{0}^{*}$ \\
\hline
\end{tabular}

The channel at time $\mathrm{t}$ may be modeled by a complex multiplicative distortion $h_{0}(t)$ for transmit antenna zero and $h_{l}(t)$ for transmit antenna one. Assuming that fading is constant across two consecutive symbols, we can write:

$$
\begin{aligned}
& \mathrm{h}_{0}(\mathrm{t})=\mathrm{h}_{0}(\mathrm{t}+\mathrm{T})=\mathrm{h}_{0}=\alpha_{0} \mathrm{e}^{\mathrm{j} \theta_{0}} \\
& \mathrm{~h}_{1}(\mathrm{t})=\mathrm{h}_{1}(\mathrm{t}+\mathrm{T})=\mathrm{h}_{1}=\alpha_{1} \mathrm{e}^{\mathrm{j} \theta_{1}}
\end{aligned}
$$

where $\mathrm{T}$ is the symbol duration. The received signals can then be expressed as:

$$
\begin{aligned}
& \mathrm{r}_{0}=\mathrm{r}(\mathrm{t})=\mathrm{h}_{0} \mathrm{~s}_{0}+\mathrm{h}_{1} \mathrm{~s}_{1}+\mathrm{n}_{0} \\
& \mathrm{r}_{1}=\mathrm{r}(\mathrm{t}+\mathrm{T})=-\mathrm{h}_{0} \mathrm{~s}_{1}^{*}+\mathrm{h}_{1} \mathrm{~s}_{0}^{*}+\mathrm{n}_{1}
\end{aligned}
$$

Where $r_{0}$ and $r_{1}$ are the received signals at time $t$ and $t+T$ and $n_{0}$ and $n_{1}$ are complex random variables representing receiver noise and interference.[4]

\subsubsection{The Combining Scheme}

The combiner builds the following two combined signals that are sent to the maximum likelihood detector:

$$
\begin{aligned}
& \widetilde{\mathrm{S}_{0}}=\mathrm{h}_{0}^{*} \mathrm{r}_{0}+\mathrm{h}_{1} \mathrm{r}_{1}^{*} \\
& \widetilde{\mathrm{S}_{1}}=\mathrm{h}_{1}^{*} \mathrm{r}_{0}-\mathrm{h}_{0} \mathrm{r}_{1}^{*}
\end{aligned}
$$

It is important to note that this combining scheme is different from MRRC substituting the appropriate equations we have:

$$
\begin{aligned}
& \widetilde{\mathrm{S}_{0}}=\left(\alpha_{0}^{2}+\alpha_{1}^{2}\right) \mathrm{s}_{0}+\mathrm{h}_{0}^{*} \mathrm{n}_{0}+\mathrm{h}_{1} \mathrm{n}_{1}^{*} \\
& \widetilde{\mathrm{S}_{1}}=\left(\alpha_{0}^{2}+\alpha_{1}^{2}\right) \mathrm{s}_{1}-\mathrm{h}_{0} \mathrm{n}_{1}^{*}+\mathrm{h}_{1}^{*} \mathrm{n}_{0}
\end{aligned}
$$

\subsection{Two-Branch Transmit Diversity with M Receivers}

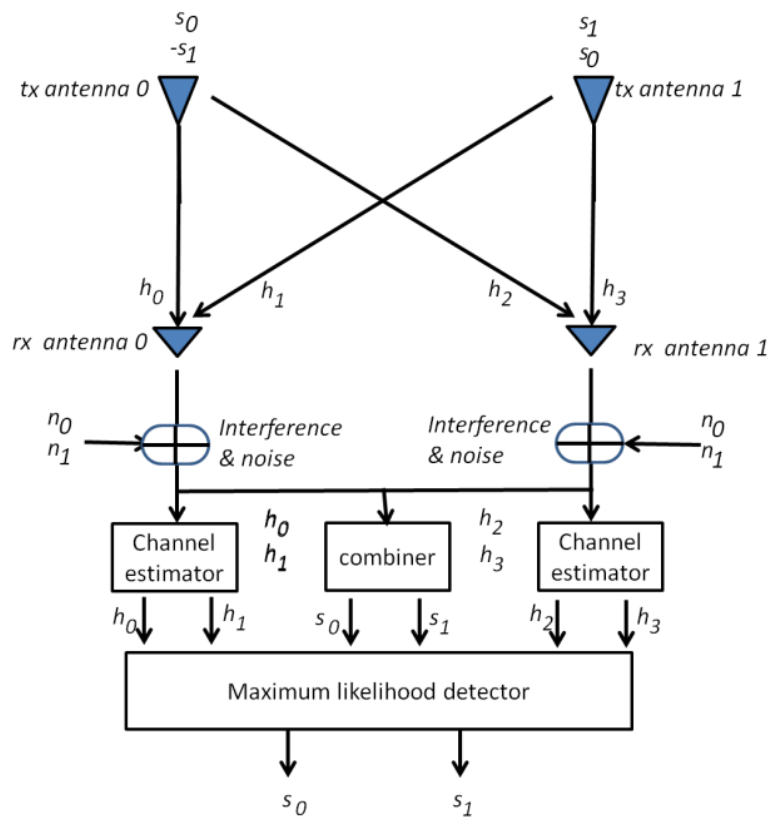

Fig. 2

There may be applications where a higher order of diversity is needed and multiple receive antennas at the remote units are feasible. In such cases, it is possible to provide a diversity order of $2 \mathrm{M}$ with two transmit and $\mathrm{M}$ receive antennas. For illustration, we discuss the special case of two transmit and two receive antennas in detail. The generalization to $\mathrm{M}$ receive antennas is trivial.The new twobranch transmit diversity scheme with two receivers.[2]

Table B. The definition of channels between the transmit and receive antennas.

\begin{tabular}{|c|c|c|}
\hline & $\mathbf{r}_{\mathbf{x}}$ antenna 0 & $\begin{array}{c}\mathbf{r}_{\mathbf{x}} \\
\text { antenna 1 }\end{array}$ \\
\hline $\mathrm{T}_{\mathrm{x}}$ antenna 0 & $\mathrm{h}_{0}$ & $\mathrm{~h}_{2}$ \\
\hline $\mathrm{t}_{\mathrm{x}}$ antenna 1 & $\mathrm{h}_{1}$ & $\mathrm{~h}_{3}$ \\
\hline
\end{tabular}


Table $\mathrm{C}$. The notation for the received signals at the two receive antennas.

\begin{tabular}{|c|c|c|}
\hline & $\mathbf{r}_{\mathbf{x}}$ antenna 0 & $\mathbf{r}_{\mathbf{x}}$ antenna 1 \\
\hline $\mathrm{T}$ & $\mathrm{r}_{0}$ & $\mathrm{r}_{2}$ \\
\hline $\mathrm{t}+\mathrm{T}$ & $\mathrm{r}_{1}$ & $\mathrm{r}_{3}$ \\
\hline
\end{tabular}

For this configuration the encoding and transmission sequence of the information symbols is identical to the case of a single receiver, shown in Table A. Table B. defines the channels between the transmit and receive antennas, Table C. defines the notation for the received signal at the two receive antennas, where:

(9)

$$
\begin{gathered}
\mathrm{r}_{0}=\mathrm{h}_{0} \mathrm{~s}_{0}+\mathrm{h}_{1} \mathrm{~s}_{1}+\mathrm{n}_{0} \\
\mathrm{r}_{1}=-\mathrm{h}_{0} \mathrm{~s}_{1}^{*}+\mathrm{h}_{1} \mathrm{~s}_{0}^{*}+\mathrm{n}_{1} \\
\mathrm{r}_{2}=\mathrm{h}_{2} \mathrm{~s}_{0}+\mathrm{h}_{3} \mathrm{~s}_{1}+\mathrm{n}_{2} \\
\mathrm{r}_{3}=-\mathrm{h}_{2} \mathrm{~s}_{1}^{*}+\mathrm{h}_{3} \mathrm{~s}_{0}^{*}+\mathrm{n}_{3}
\end{gathered}
$$

$\mathrm{n}_{\mathrm{o}}, \mathrm{n}_{1}, \mathrm{n}_{2}$ and $\mathrm{n}_{3}$ are complex random variables representing receiver thermal noise and interference. The combiner in builds the following two signals that are sent to the maximum likelihood detector:

$$
\begin{gathered}
\widetilde{s_{0}}=h_{0}^{*} r_{0}+h_{1} r_{1}^{*}+h_{2}^{*} r_{2}+h_{3} r_{3}^{*} \\
\widetilde{s_{1}}=h_{1}^{*} r_{0}-h_{0} r_{1}^{*}+h_{3}^{*} r_{2}-h_{2} r_{3}^{*}
\end{gathered}
$$

Substituting the appropriate equations we have:

$\widetilde{s_{0}}=\left(\alpha_{0}^{2}+\alpha_{1}^{2}+\alpha_{2}^{2}+\alpha_{3}^{2}\right) s_{0}+h_{0}^{*} n_{0}+h_{1} n_{1}^{*}+h_{2}^{*} n_{2}+h_{3} n_{3}^{*}$ $\widetilde{s_{1}}=\left(\alpha_{0}^{2}+\alpha_{1}^{2}+\alpha_{2}^{2}+\alpha_{3}^{2}\right) s_{1}-h_{0} n_{1}^{*}+n_{0} h_{1}^{*}-h_{2} n_{3}^{*}+h_{3}^{*} n_{2}$

These combined signals are then sent to the maximum likelihood detector which for signal $\mathrm{s}_{0}$ uses the decision criteria for PSK signals.

Choose $s_{\mathrm{i}}$ iff:

$$
\begin{gathered}
\left(\alpha_{0}^{2}+\alpha_{1}^{2}+\alpha_{2}^{2}+\alpha_{3}^{2}-1\right)\left|s_{i}\right|^{2}+d^{2}\left(\widetilde{s_{0}}, s_{i}\right) \\
\leq\left(\alpha_{0}^{2}+\alpha_{1}^{2}+\alpha_{2}^{2}+\alpha_{3}^{2}-1\right)\left|s_{k}\right|^{2}+d^{2}\left(\widetilde{s_{0}}, s_{k}\right)
\end{gathered}
$$

Choose $s_{i}$ iff:

$$
\mathrm{d}^{2}\left(\widetilde{\mathrm{s}_{0}}, \mathrm{~s}_{\mathrm{i}}\right) \leq \mathrm{d}^{2}\left(\widetilde{\mathrm{s}_{0}}, \mathrm{~s}_{\mathrm{k}}\right), \quad \forall \mathrm{i} \neq \mathrm{k}
$$

Similarly, for $\mathrm{s}_{1}$, using the decision rule is to choose signal $\mathrm{s}_{\mathrm{i}}$ iff:

$$
\begin{gathered}
\left(\alpha_{0}^{2}+\alpha_{1}^{2}+\alpha_{2}^{2}+\alpha_{3}^{2}-1\right)\left|s_{\mathrm{i}}\right|^{2}+\mathrm{d}^{2}\left(\widetilde{\mathrm{s}_{1}}, \mathrm{~s}_{\mathrm{i}}\right) \\
\leq\left(\alpha_{0}^{2}+\alpha_{1}^{2}+\alpha_{2}^{2}+\alpha_{3}^{2}-1\right)\left|s_{\mathrm{k}}\right|^{2}+\mathrm{d}^{2}\left(\widetilde{\mathrm{s}_{1}}, \mathrm{~s}_{\mathrm{k}}\right)
\end{gathered}
$$

or, for PSK signals, choose $s_{i}$ iff:

$$
\mathrm{d}^{2}\left(\widetilde{\mathrm{s}_{1}}, \mathrm{~s}_{\mathrm{i}}\right) \leq \mathrm{d}^{2}\left(\widetilde{\mathrm{s}_{1}}, \mathrm{~s}_{\mathrm{k}}\right), \quad \forall \mathrm{i} \neq \mathrm{k} .
$$

The combined signals are equivalently to that of four branches MRRC. Therefore, the resulting diversity order from the new two- branch transmit diversity scheme with two receivers is equal to that of the four-branch MRRC scheme. $[3,6]$

\section{RESULTS AND CONCLUSION}

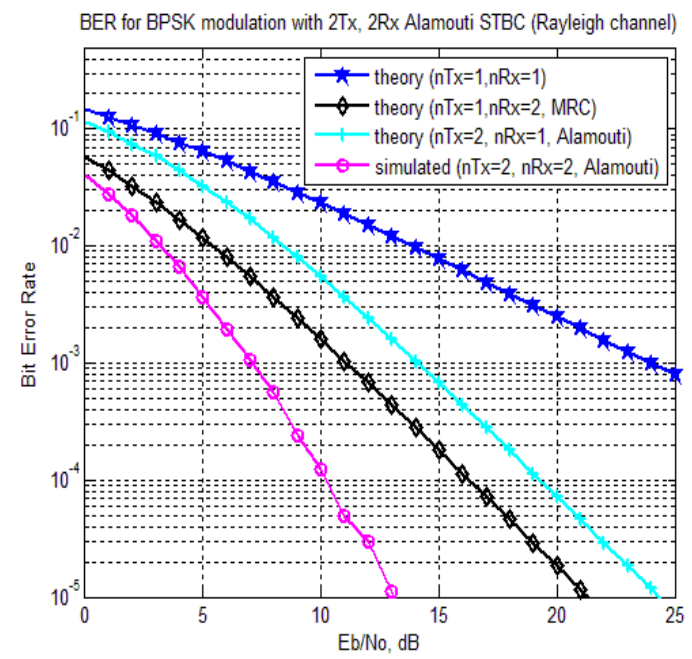

The BER Performance comparison for BPSK with MRC Fig. 3

The bit error rate performance of a 2-Tx \& 2-Rx MIMO in Rayleigh fading environment is shown in given figure

BER for BPSK Modulation with Maximal Ratio Combining in Rayleigh

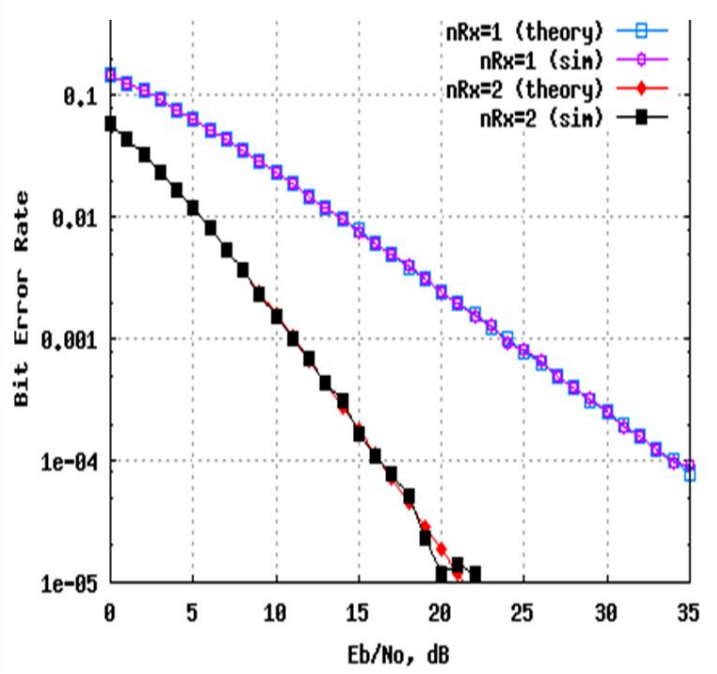

Fig. 4

At $\mathrm{Eb} / \mathrm{No}=10 \mathrm{db}$ the bit error rate for $2 \mathrm{x} 2 \mathrm{MIMO}$ system is $10^{-4}$ and for 1 transmits 2 receive MRC case the bit error rate for $\mathrm{Eb} / \mathrm{No}=10 \mathrm{db}$ is around $10^{-4}$. i.e for any value of $\mathrm{Eb} / \mathrm{No}$ the BER is:

$2 \mathrm{Tx}, 2 \mathrm{Rx}<2 \mathrm{Tx}, 1 \mathrm{Rx}<1 \mathrm{Tx}, 2 \mathrm{Rx}(\mathrm{MRC})<1 \mathrm{Tx}, 1 \mathrm{Rx}$.

So it is confirms that the BER performance of $2 \times 2$ MIMO System is much better than 1 transmits 2 receive MRC case. 


\section{REFERENCES}

[1] Upena Dalal, 2009. Wireless Communications: Oxford University Press

[2] Mohd. S. Aljerjawi, and Walaa Hamouda, "Performance Analysis of multiuser DS-CDMA in MIMO systems over Rayleigh channels," IEEE Trans.Veh. technology, Vol.57, No.3 May 2008.

[3] Juha Ylitalo, "Double Directional Beamforming MIMO A simulation study",VTC spring 2007:2063-2067.

[4] T. S. Pollock, T. D. Abhayapala, and R. A. Kennedy, "Introducing space into MIMO capacity calculations," Journal on Telecommunication Systems, vol. 24, no. 24, pp. 415-436, 2003
[5] Rappaport, T.S. 2002. Wireless Communications: Principles and Practice.

[6] S. Jayaweera and H. V. Poor, "Low complexity receiver structures for space-time coded multiple-access systems," EURASIP J. Appl. SignalProcess. (Special Issue on Space-Time Coding), vol. 2002, no. 3, pp. 275-288, Mar. 2002

[7] E. Telatar, Capacity of multi-antenna Gaussian channels. European Trans. on Telecom., vol. 10, no. 6 , pp. 585-595, Nov.-Dec. 1999.

[8] G.J. Foschini and M.J. Gans, "On limits of wireless communications in a fading environment when using multiple antennas," Wireless Personal Communications, vol. $6, \quad$ pp. 311-335, 1998 